\title{
Chronic Bronchobronchiolitis Obliterans Associated with Stevens-Johnson Syndrome
}

\author{
Jun Yatsunami, Yoichi NaKanishi, Hiroaki Matsuki, Kentaro WaKamatsu, Koichi TaKayama, \\ Masayuki Kawasaki, Hideo Ogino, Shuichi Hashimoto and Nobuyuki Hara
}

\begin{abstract}
We report a case of bronchobronchiolitis obliterans associated with Stevens-Johnson syndrome diagnosed using bronchography and bronchoscopy in a 25-year-old man with dyspnea. Eighteen months prior to admission, the diagnosis of Stevens-Johnson syndrome due to anticonvulsant therapy was made at another hospital. On admission, the patient was wheezing and had overinflation of the lungs, with marked obstructive pulmonary dysfunction. Ventilation and perfusion scintigrams revealed multiple ventilation and perfusion defects but not mismatch. Bronchography revealed central bronchiectasis and obstruction of the peripheral bronchi. Occlusion of the fifth right basal bronchus was observed with fiberoptic bronchoscopy. Bronchography and bronchoscopy provide useful information for the diagnosis of this disease.
\end{abstract}

(Internal Medicine 34: 772-775, 1995)

Key words: obliterative bronchobronchiolitis, erythema multiforme, bronchography, bronchial occlusion

\section{Introduction}

Stevens-Johnson syndrome is an erythema multiforme characterized by a polymorphorus vesicular and bullous eruption of the skin and mucosa, with systemic manifestations of variable severity $(1,2)$. Underlying causes include various microbial diseases, exposure to drugs, malignant tumors, and connective tissue diseases (3). Bronchopulmonary involvement is thought to be rare except in cases that are caused by mycoplasma infection (1). The unique characteristic of bronchopulmonary complications termed "obliterative bronchitis" or "bronchobrochiolitis obliterans" have been previously diagnosed only by postmortem examination $(4,5)$. We report a patient with bronchobronchiolitis obliterans associated with drug-induced Stevens-Johnson syndrome, who was diagnosed clinically and on the basis of bronchography and bronchoscopic findings.

\section{Case Report}

A 25-year-old man was admitted to our hospital with the chief complaint of dyspnea in December 1993. He had a subarachinoid hemorrhage due to a traffic accident in June 1992, and received treatment for it at another hospital. Otherwise his past medical history was unremarkable. During the treatment he had a high fever, generalized vesicular rash, and severe conjunctivitis. He also developed mucopurulent sputum and melena. The patient was diagnosed as Stevens-Johnson syndrome clinically and by skin biopsy, which was attributed to an anticonvulsant drug, phenytoin. He was treated with corticosteroids and discharged 8 months later, when his respiratory symptoms had almost resolved except for exertional dyspnea.

After discharging from the hospital, he had progressive dyspnea and wheezing and was treated as chronic bronchiolitis. However his response to bronchodilators and antibiotics was poor. In December 1993, he was admitted to our hospital for evaluation of his pulmonary disease. On admission, he demonstrated a saddle nose due to destruction of the nasal septal cartilage, conjunctival xerosis secondary to conjunctival adhesions, and scars of oral mucosa. Wheeze was audible in bilateral chest auscultation, otherwise unremarkable in physical examination. Laboratory findings were almost all within the normal range (Table 1), including a serum $\alpha_{1}$-antitrypsin concentration. Sputum cultures demonstrated a normal flora. An arterial blood gas revealed a pH of 7.362, $\mathrm{PCO}_{2}$ of $46.2 \mathrm{mmHg}$, and $\mathrm{PO}_{2}$ of $67.7 \mathrm{mmHg}$, with oxygen saturation of $92 \%$ in room air. Pulmonary function tests revealed a severe obstructive pattern with a marked increase in residual volume (Table 1). This

From the Research Institute for Diseases of the Chest, Faculty of Medicine, Kyushu University, Fukuoka

Received for publication October 31, 1994; Accepted for publication April 26, 1995

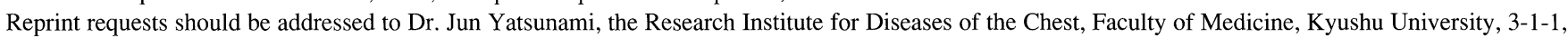
Maidashi, Higashiku, Fukuoka 812 


\section{Chronic Obliterative Bronchobronchiolitis}

Table 1. Laboratory Data on Admission

\begin{tabular}{|c|c|c|c|}
\hline Hematology & \multicolumn{3}{|c|}{ Serology } \\
\hline White blood cell & $7,720 / \mathrm{mm}^{3}$ & C-reactive protein & $0.3 \mathrm{mg} / \mathrm{ml}$ \\
\hline Neutrophils & $42 \%$ & $\operatorname{IgG}$ & $1,436 \mathrm{mg} / \mathrm{ml}$ \\
\hline Lymphocytes & $44 \%$ & $\operatorname{IgA}$ & $331 \mathrm{mg} / \mathrm{ml}$ \\
\hline Monocytes & $6 \%$ & $\operatorname{Ig} M$ & $166 \mathrm{mg} / \mathrm{ml}$ \\
\hline Eosinophils & $6 \%$ & $\operatorname{IgE}$ & $<33 \mathrm{IU} / \mathrm{ml}$ \\
\hline Red blood cell & $71 \times 10^{4} / \mathrm{mm}^{3}$ & Rheumatoid factor & - \\
\hline Hemoglobin & $16.3 \mathrm{~g} / \mathrm{dl}$ & Antinuclear factor & - \\
\hline Hematocrit & $48.6 \%$ & HTLV-1 Ab & - \\
\hline Platelets & $.7 \times 10^{4} / \mathrm{mm}^{3}$ & CA-T & $<16$ \\
\hline Erythrocyte sedimentatior & on rate $6 / 11$ & Mycoplasma T & $<40$ \\
\hline Blood chemistry & \multicolumn{3}{|c|}{ Pulmonary function test } \\
\hline Total protein & $7.6 \mathrm{~g} / \mathrm{ml}$ & $\mathrm{VC}$ &, $760 \mathrm{ml}(76 \%)$ \\
\hline Albumin & $67.6 \%$ & RV & $6,210 \mathrm{ml}$ \\
\hline$\alpha_{1}$-globulin & $2.6 \%$ & TLC & $6,970 \mathrm{ml}$ \\
\hline$\alpha_{2}$-globulin & $9.2 \%$ & $\mathrm{RV} / \mathrm{TLC}$ & $69 \%$ \\
\hline B-globulin & $5.3 \%$ & FVC & $1,810 \mathrm{ml}$ \\
\hline$\gamma$-globulin & $12.1 \%$ & $\mathrm{FEV}_{1.0}$ & $550 \mathrm{ml}$ \\
\hline Blood urea nitrogen & $12 \mathrm{mg} / \mathrm{dl}$ & $\mathrm{FEV}_{1.0}$ & $29 \%$ \\
\hline Creatinine & $0.9 \mathrm{mg} / \mathrm{dl}$ & & \\
\hline $\mathrm{Na}$ & $140 \mathrm{mEq} / \mathrm{l}$ & Arterial blood gas & \\
\hline $\mathrm{K}$ & $4.5 \mathrm{mEq} / \mathrm{l}$ & $\mathrm{pH}$ & 7.362 \\
\hline $\mathrm{Cl}$ & $104 \mathrm{mEq} / \mathrm{l}$ & $\mathrm{PaO}_{2}$ & $67.7 \mathrm{mmHg}$ \\
\hline Aspartate aminotransferase & $23 \mathrm{IU} / l$ & $\mathrm{PaCO}_{2}$ & $46.2 \mathrm{mmHg}$ \\
\hline Alanine aminotransferase & $11 \mathrm{IU} / l$ & $\mathrm{BE}$ & 2.2 \\
\hline Lactate dehydrogenase & $334 \mathrm{IU} / l$ & $\mathrm{SaO}_{2}$ & $91.9 \%$ \\
\hline Alkaline phosphatase & $206 \mathrm{IU} / \mathrm{l}$ & & \\
\hline$\gamma$-glutamyltranspeptidase & $47 \mathrm{IU} / \mathrm{l}$ & & \\
\hline$\alpha_{1}$-antitrypsin & $160 \mathrm{ng} / \mathrm{dl}$ & & \\
\hline
\end{tabular}

HTLV-1, Ab: human T cell leukemia virus Ab, CA-T: cold agglutinin test, VC: vital capacity, RV: resifual volume, TLC: forced vital capacity, FVC: forced vital capacity, $\mathrm{FEV}_{1.0}$ : forced expiratory volume, BE: base excess.

obstructive dysfunction did not improve following the inhal tion of bronchodilators. A chest radiograph revealed bilater hyperlucencies but no significant opacities (Fig. 1). Comput tomographic scan of the chest demonstrated hyperlucent lun. with narrowing of the peripheral vessels. Ventilation as perfusion scintigrams demonstrated multiple ventilation as perfusion defects without a mismatch (Fig. 2). These $d c$ suggested the existence of multiple obstructions of the bronc and, or bronchioli. Selective bronchography of the right low bronchi revealed mild central bronchiectasis of the segmen bronchi and obstruction of the peripheral bronchi (Fig. ' Bronchoscopy performed using an Olympus type $3 \mathrm{C} 10$ bro choscope demonstrated "conical" occlusion of the fifth bro chus (rt. $\mathrm{B}_{9}$ aia, Fig. 4). On the basis of these findings, diagnosis of bronchobronchiolitis obliterans was made. $\mathrm{V}$ treated the patient with $50 \mathrm{mg} /$ day of oral prednisolone, $\mathrm{b}$

Figure 1. Chest radiograph on admission demonstrated hyperinflation of the lungs with no significant opacities.

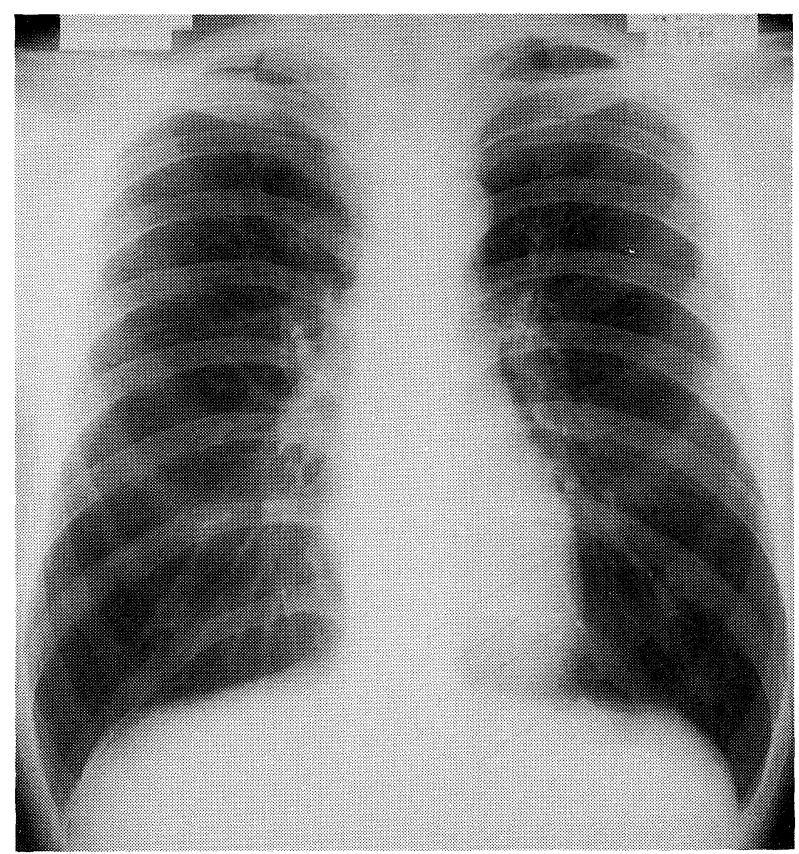



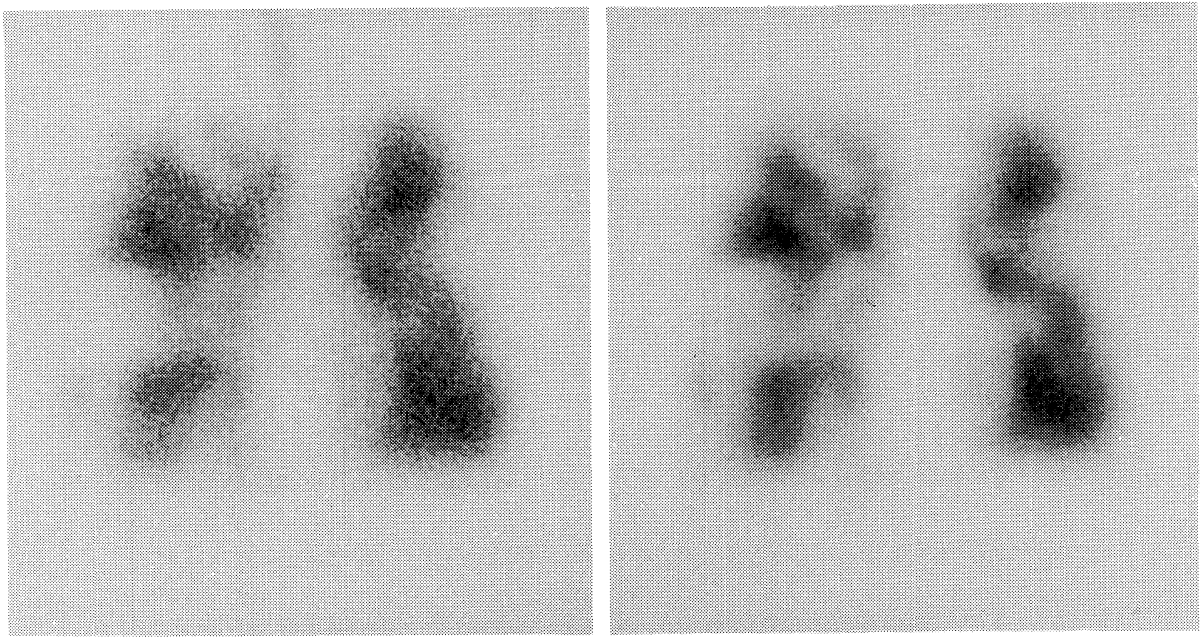

Figure 2. ${ }^{99 \mathrm{~m}} \mathrm{Tc}-\mathrm{MAA}$ lung perfusion scintigraphy (right) and ${ }^{81 \mathrm{~m}} \mathrm{Kr}$ lung ventilation scintigraphy (left). These scintigraphic studies revealed multiple defects but no mismatch.

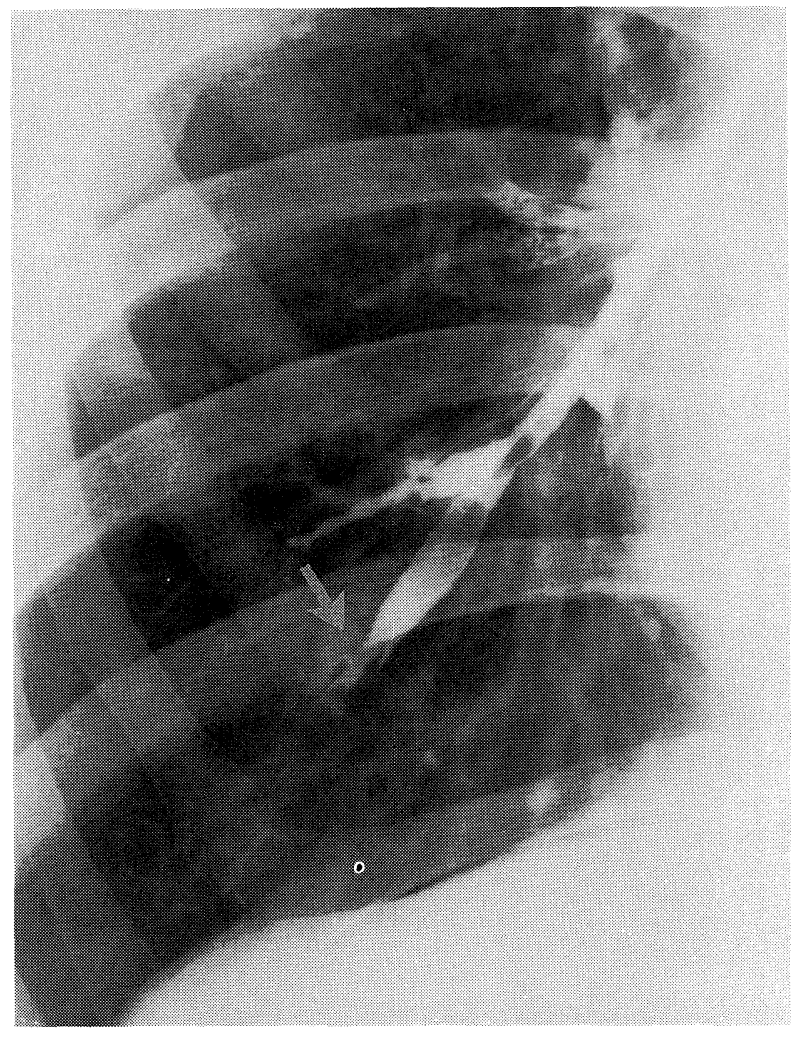

Figure 3. Selective bronchography of the right lower lobe shows cylindrical bronchiectasis of $B_{9}$ and occlusion of the peripheral bronchi (arrow).

neither his symptoms nor obstructive pulmonary dysfunction improved. After tapering off the prednisolone, he was discharged and treated with low dose erythromycin and bronchodilaters.

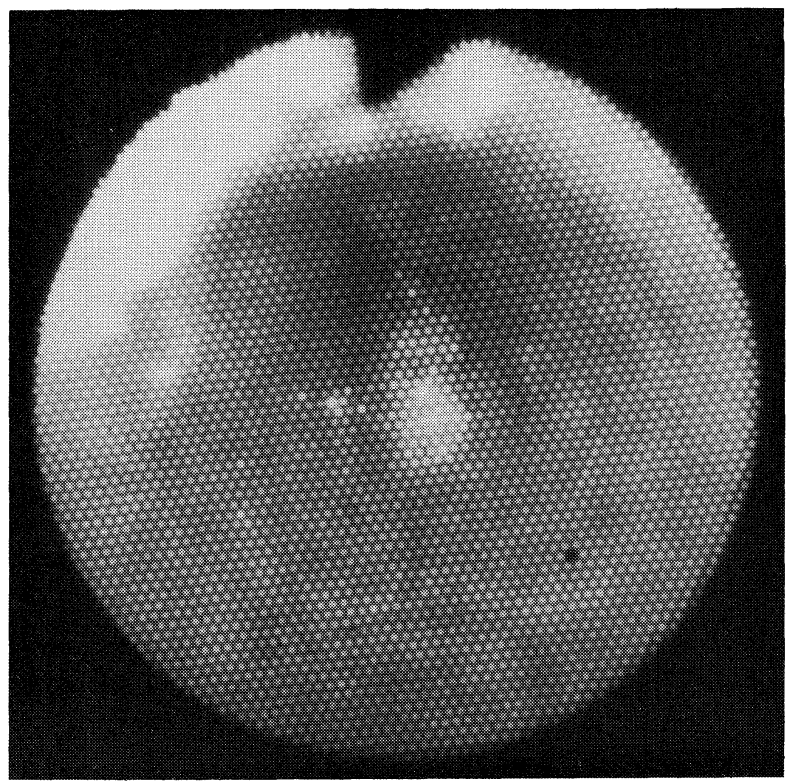

Figure 4. Bronchoscopy of right $B_{9}$ ai $\alpha$ shows an abrupt occlusion of the bronchus.

\section{Discussion}

In 1986, Yamanaka et al. proposed "bronchobronchiolitis obliterans" as a pathologic entity (6). They described eight patients with obstructive changes of both the bronchi and bronchioli that were identified at autopsy. The underlying diseases of one of these cases was Stevens-Johnson syndrome. In that case, small bronchial lumens were obliterated by fibrous granulation tissues. Sites that were affected by this disease include the small bronchi, such as cartilaginous bronchi, and non-respiratory bronchioli, while diffuse panbronchiolitis in- 


\section{Chronic Obliterative Bronchobronchiolitis}

volves the respiratory bronchioli. Despite the absence of histopathological evidence, we believe that the present case belongs to the former category. Although we performed transbronchial lung biopsy, a biopsy specimen revealed only chronic inflammatory changes of broncho-alveolar tissue. To our knowledge, there have been no cases of this disease which were diagnosed pathologically by open lung biopsy or transbronchial lung biopsy. We did not perform an open lung biopsy because the patient had very poor pulmonary function and there have been no reports documenting an effective therapy for this pulmonary disease.

The cause of this disease is uncertain. There have been some reports of underlying diseases other than Stevens-Johnson syndrome, such as rheumatoid arthritis, and Castleman's lymphoma, which suggest that an immunological disorder might be associated with this disease (6). However, in our patient, we think, at the time of Stevens-Johnson syndrome, granulation of fibrous tissue overproliferated to heal necrolysis of the bronchial mucosa and obliterated the bronchial lumen. Mild central bronchiectasis may have occurred secondarily. There have been two reports of bronchiectasis following mycoplasma pneumonia associated with Stevens-Johnson syndrome $(1,7)$, in which one patient was diagnosed as bronchitis obliterans (4).

No effective therapy has been reported for patients after obliterative changes have been established. We treated our patient with prednisolone to rule out an asthmatic component to this disease, but no beneficial effects were observed. It is suggested that patients with proximal bronchial obstruction suffer a more severe clinical course, compared with patients with other types of bronchiolitis obliterans and diffuse panbronchiolitis.

Selective bronchography and fiberoptic bronchoscopy were very useful in demonstrating the bronchial occlusion in the present case; these analyses verified the radiologist's diagnosis of panlobular emphysema. Bronchography is rarely performed due to the recent popularity of computed tomographic scan. We used non-ionic contrast media, iopamidol with $2 \%$ carboxymethyl cellulose instead of propylidone (Dionosil) because propylidione is now not commercially available (8). In the present case, even with high resolution computed tomographic scan, we could not detect the obliteration of bronchi. We did observe the obliteration sites of bronchi using a bronchofiber scope (Olympus type $3 \mathrm{C} 10$ ) placed at the fifth bronchus of the right lower lobe. Since occlusions of the third to fifty bronchi containing cartilage have been reported $(1,4,5,9)$, the macroscopic finding with a bronchofiber of a small diameter was useful. Taking into consideration the poor prognosis of patients with bronchobronchiolitis obliterans and the difficulty in making a pathological diagnosis by biopsy specimens, bronchography and bronchoscopy appear to be the final diagnostic approach.

In conclusion, we think this disease can be diagnosed clinically, if patients have 1) dyspnea and wheezing which do not improve by bronchodilators or corticosteroids, 2) severe obstructive pulmonary dysfunction, 3) obstructive changes in relatively central bronchi which are confirmed by bronchography and bronchoscopical findings. Early detection of respiratory involvement and adequate therapy for Stevens-Johnson syndrome may prevent severe respiratory complications.

\section{References}

1) Stitt YJ Jr. Stevens-Johnson syndrome: A review of the literature. J Nat Med Assoc 80: 104, 1988.

2) Huff JC, Weston WL, Tonnesen MG. Erythema multiforme: A critical review of characteristics, diagnostic criteria, and causes. J Am Acad Dermatol 8: 765, 1983.

3) Patterson R, Dykewicz MS, Gonzalzles A, et al. Erythema multiforme and Stevens-Johnson syndrome: Descriptive and therapeutic controversy. Chest 98: 331, 1990.

4) Edwards C, Penny M, Newman J. Mycoplasma, Stevens-Johnson syndrome, and chronic obliterative bronchitis. Thorax 38: 867, 1983.

5) Tsunoda N, Iwanaga T, Saito J, Kitamura S, Saito K. Rapidly progressive bronchiolitis obliterans associated with Stevens-Johnson syndrome. Chest 98: 243, 1990.

6) Yamanaka A, Maeda M, Yamamoto R. Bronchobronchiolitis obliterans. Jpn J Chest Dis 45: 540, 1986 (in Japanese).

7) Whyte KF, Williams GR. Bronchiectasis after mycoplasma pneumonia. Thorax 39: 390, 1984.

8) Matsuki H, Nakanishi Y, Yatsunami J, Hara N. Use of non-ionic contrast media for bronchography. J Jpn Soc Bronch 16: 336, 1994 (in Japanese).

9) Takizawa T. Bronchobronchilitis obliterans. Lung and Heart 37: 202, 1990 (in Japanese). 